\title{
KNOWLEDGE ABOUT DENTIN HYPERSENSITIVITY: A QUESTIONNAIRE-BASED SURVEY AMONG DENTAL STUDENTS AND YOUNG DENTISTS
}

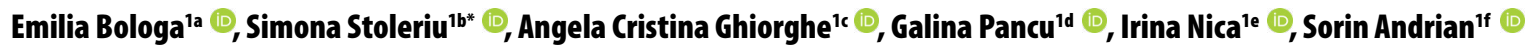 \\ 'Department of Odontology, Periodontology and Fixed Prosthodontics, Faculty of Dental Medicine, Grigore T. Popa University of Medicine and Pharmacy \\ of Jassy, Jassy, Romania
}

\author{
aDDS, PhD Student; e-mail: bologa.emilia@umfiasi.ro; ORCIDiD: https://orcid.org/0000-0002-0091-8765 \\ bDDS, PhD, Associate Professor; e-mail: stoleriu_simona@yahoo.com; ORCIDiD: https://orcid.org/0000-0001-5427-6027 \\ 'DDS, PhD, Lecturer; e-mail: cristina.ghiorghe@umfiasi.ro; ORCIDiD: https://orcid.org0000-0002-1636-6686 \\ dDDS, PhD, Lecturer: galina.pancu@umfasi.ro; ORCIDiD: https://orcid.org/0000-0001-9593-1884 \\ eDDS, PhD, Assistant Professor: irina.nica@umfiasi.ro; ORCIDiD: https://orcid.org/0000-0003-1189-0785 \\ 'DDS, PhD, Professor: sorin.andrian@umfiasi.ro; ORCIDiD: https://orcid.org/0000-0002-9271-6123
}

\section{ABSTRACT}

d) https://doi.org/10.25241/stomaeduj.2020.7(3).art.3

Introduction Continued education is a fundamental characteristic of one's working life, especially in the medical field. Keeping up to date should be a mandatory element of dental practice. Dentin hypersensitivity (DH) has been a long-term significant challenge for practitioners due to the uncertainties around its diagnosis and treatment. The aim of this study is to assess the knowledge of senior dental students and young doctors with respect to this dental pathology.

Methodology A total of 632 self-administered questionnaire were distributed to dental students and doctors for data collection. The 10 questions investigated the knowledge about the description of pain in $\mathrm{DH}$, triggering and predisposing factors, treatment strategies, preventive and treatment measures, remineralization products, etiological factors of dental wear, and main characteristics of $\mathrm{DH}$. The data were analyzed using SPSS 20.0. Standard descriptive statistics were computed and analytical statistical analysis was performed using Pearson's chi-square test.

Results The response rate for dental students was $87.87 \%$ and $10.2 \%$ for young doctors. Most respondents revealed a good level of knowledge regarding pain characterization, triggering factors, and predisposing factors of dentin hypersensitivity, and a satisfactory level for the disease management strategies. The average score of the questionnaire recorded at group level was 42.253.

Conclusion Young dentists had better knowledge of DH compared to 6th-year dental students. The information obtained from this study revealed that there is a need to provide better theoretical but also clinical teaching opportunities to students, as well as continued educational programs to young doctors.

\section{KEYWORDS}

Dentin Hypersensitivity; Knowledge; Dental Students; Dentists; Questionnaire.

\section{INTRODUCTION}

Dentin hypersensitivity $(\mathrm{DH})$ is a condition that has often been encountered in dental practice in recent decades [1-3], however, the historical reporting of this symptomatology goes as far back as the 16 th century $[4,5]$. Holland et al. [6] described this pathology as a short, sharp pain arising when dentin is exposed to different stimuli (typically thermal, evaporative, tactile, osmotic or chemical) and the pain cannot be ascribed to any other form of dental defect or disease. The prevalence of $\mathrm{DH}$ ranges from $1.34 \%$ to $92.1 \%$ in the adult population [1-4,7-11]. This discrepancy occurs due to the differences in the methods used for diagnosis and in the selection criteria of the subjects.

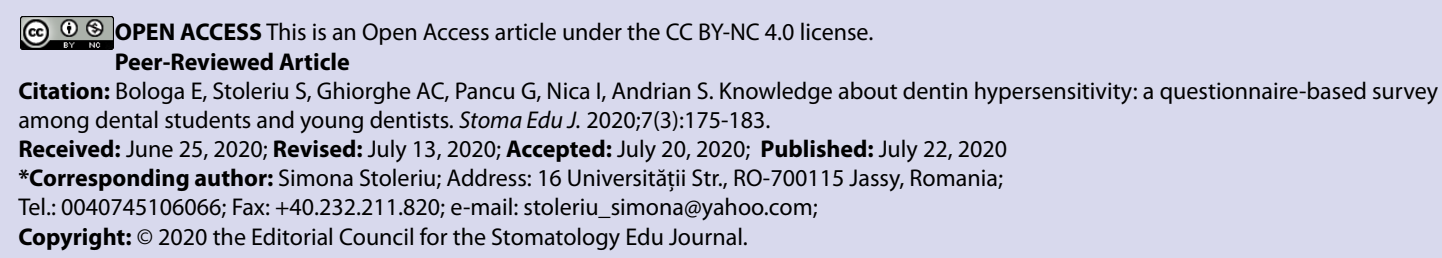




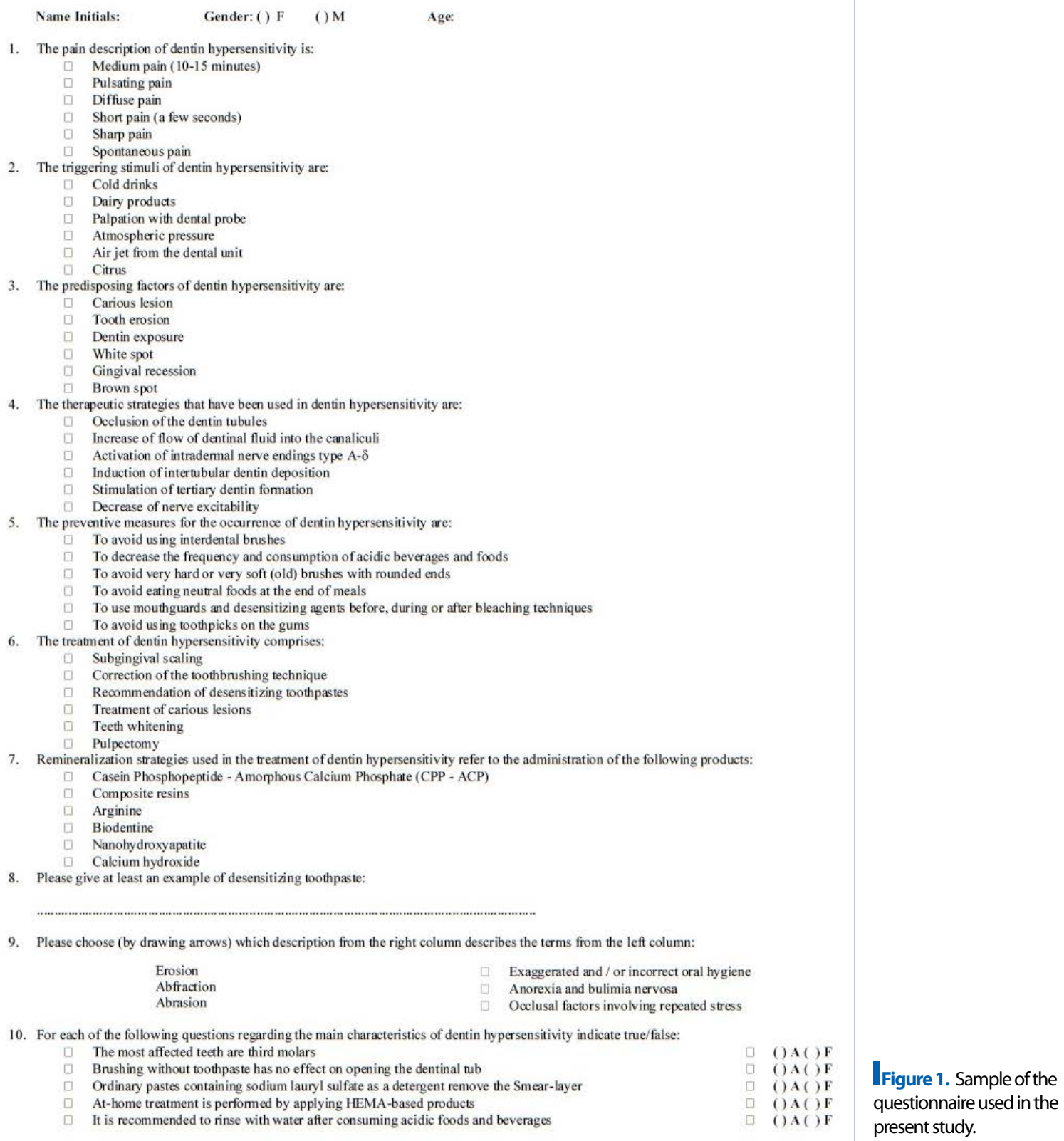

10. For each of the following questions regarding the main characteristics of dentin hypersensitivity indicate true/false: The most affected teeth are third molars

Brushing without toothpaste has no effect on opening the dentinal tub

Patients with sensitive teeth experience discomfort while eating, drinking, and brushing their teeth, all of them being considered activities that affect the quality of life $[2,12]$. The academic curricula include clinical training for students to diagnose and to treat patients with different dental diseases under supervision, and therefore they are expected to have adequate knowledge about these conditions. Dental students and beginner young dentists that no longer have a supervisor to check their work quality must be acquainted with $\mathrm{DH}$ and must have the skills to correctly manage the disease $[3,9]$.

There are limited data available regarding dental students' and young dentists' understanding of $\mathrm{DH}$, especially in Romania, where no studies have been conducted on this topic.

Questionnaires are objective tools that researchers can use to collect information about people's knowledge, beliefs, attitudes, and behavior [13]. Cross-sectional studies can be based on questionnaires, providing descriptive data on the entire population being studied. In scientific literature, several self-reported questionnaire studies assess students' or dentists' knowledge about dentin hypersensitivity $[1-4,8,9,14,15]$.

Those surveys evaluated the clinical practice of the subjects in patients with $\mathrm{DH}$ and did not assess the theoretical knowledge that they possess about this disease.

The theoretical educational processes represent the base for developing clinical skills. For this reason, we conducted a study to evaluate the knowledge of dental students and young dentists about dentin hypersensitivity regarding pain description, triggering factors, predisposing factors, diagnosis, preventive and treatment measures. The null hypothesis of the present study is that there are no differences in the evaluation of the level of knowledge between young dentists and dental students. 


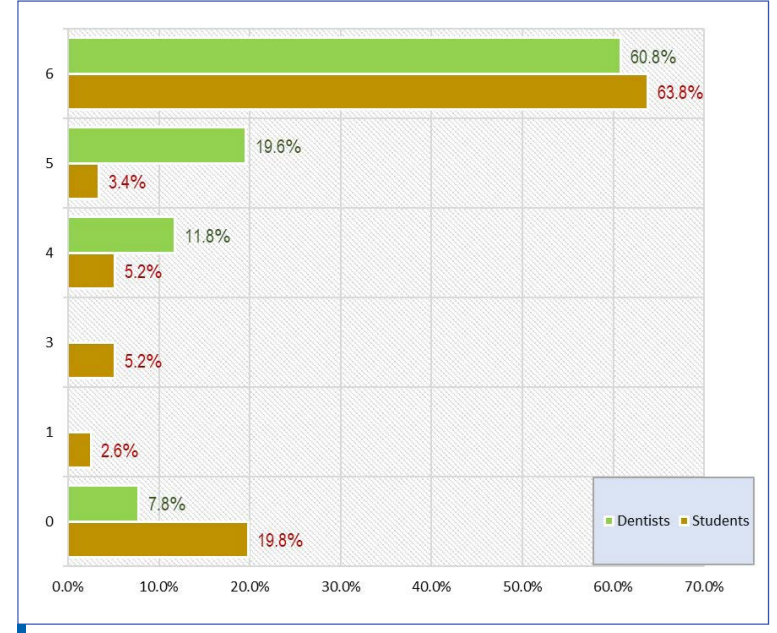

Figure 2. The distribution of scores obtained by students and dentists for Q1 (regarding the pain characteristics of DH).

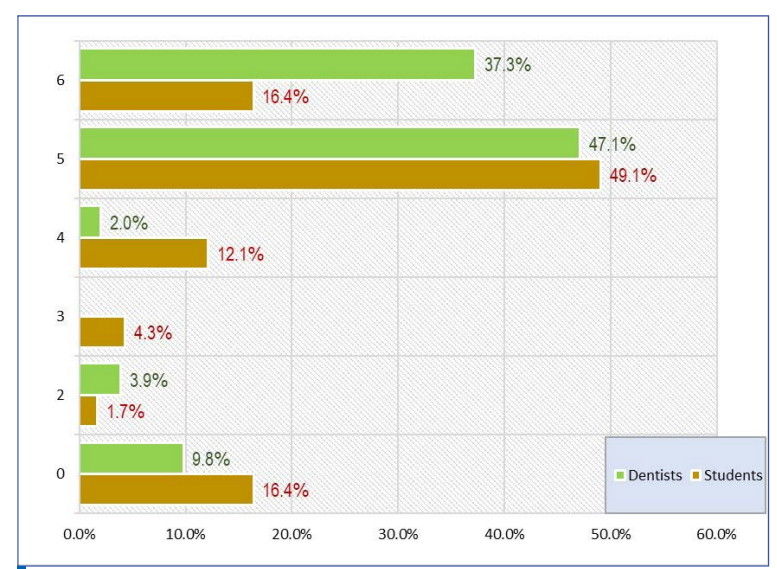

Figure 4. The distribution of scores obtained by students and dentists for Q3 (regarding the predisposing factors of DH).

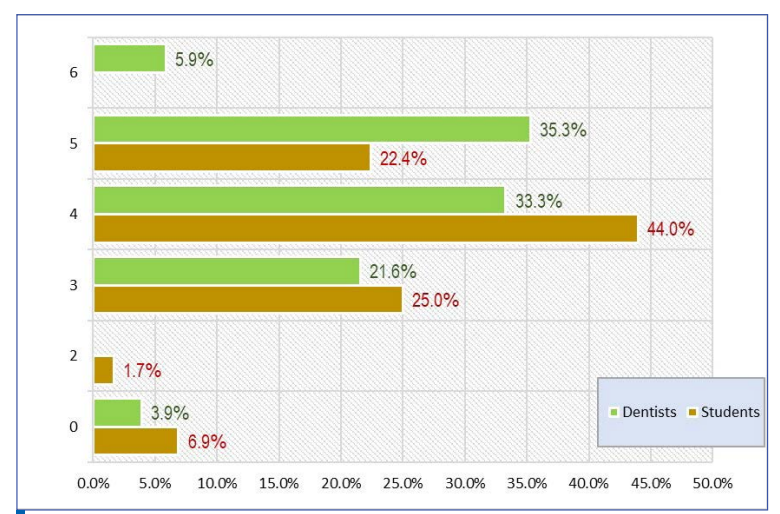

Figure 6. The distribution of scores obtained by students and dentists for Q6 (regarding the treatment of DH).

\section{MATERIAL AND METHODS}

This cross-sectional study was conducted since November 2018 till May 2019. A total of 632 questionnaires were distributed among senior dental students (6th year of study) at the Faculty of Dental Medicine - "Grigore T. Popa" University of Medicine and Pharmacy lași, Romania, and among alumni who graduated in the last five years.

All participants were informed about the purpose and the objective of this study and signed a consent form of agreement. One hundred thirty-

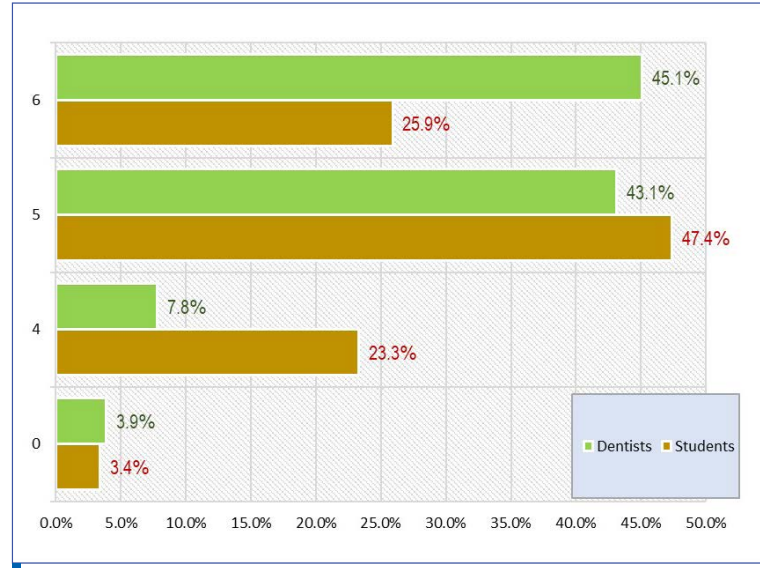

Figure 3. The distribution of scores obtained by students and dentists for Q2 (regarding the triggering factors of $\mathrm{DH}$ ).

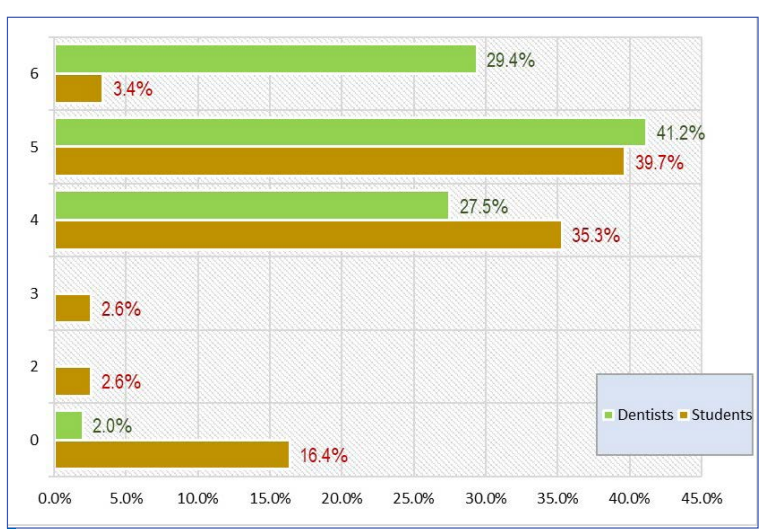

Figure 5. The distribution of scores obtained by students and dentists for Q5 (regarding the preventive measures of DH).

two dental students were asked to respond to the self-administered questionnaire at the end of their Cariology classes. Also, 500 young dentists were randomly chosen from the alumni database and received the questionnaire online. No reminder was given to those participants who did not return the questionnaire.

A literature search was performed on readily available questionnaires that measure the knowledge of dental students and young dentists about dentin hypersensitivity. None of them met the criteria to be followed in this study, so a new questionnaire was developed.

The process of developing the new questionnaire followed the recommendations of Tsang et al. [16]. The first step was to establish the expert committee, that was comprised of cariology professors, and then identify the dimensionality of the construct. It was decided that the questionnaire will be selfadministered because in this way the respondents will answer more truthfully.

The items used specific medical terminology because all the participants were trained in the dentistry field, hence being familiar with such terms. The questionnaire was constructed based on nine close-ended questions (seven multiple choice questions, one true/false question, one matrix question) and one open-ended item (Fig. 1). 
I Table 1. The qualitative assessment for the 7 multiple choice questions.

\begin{tabular}{|c|c|c|c|c|}
\hline Question & Group & Good & Satisfactory & Insufficient \\
\hline \multirow{2}{*}{$\begin{array}{r}\text { Q1 - description of the } \\
\text { pain in } \mathrm{DH}\end{array}$} & students & $67.2 \%$ & $10.3 \%$ & $22.4 \% *$ \\
\hline & dentists & $80.4 \%$ & $11.8 \%$ & $7.8 \% *$ \\
\hline \multirow{2}{*}{ Q2 - triggering factors } & students & $73.3 \% *$ & $23.3 \% *$ & $3.4 \%$ \\
\hline & dentists & $88.2 \% *$ & $7.8 \% *$ & $3.9 \%$ \\
\hline \multirow{2}{*}{ Q3 - predisposing factors } & students & $65.5 \% *$ & $16.4 \% *$ & $18.1 \%$ \\
\hline & dentists & $84.3 \% *$ & $2.0 \% *$ & $13.7 \%$ \\
\hline \multirow{2}{*}{ Q4 - treatment strategies } & students & $32.8 \% *$ & $32.8 \%$ & $34.5 \% *$ \\
\hline & dentists & $60.8 \% *$ & $31.4 \%$ & $7.8 \% *$ \\
\hline \multirow{2}{*}{$\begin{array}{r}\text { Q5 - preventive } \\
\text { measures }\end{array}$} & students & $43.1 \% *$ & $37.9 \%$ & $19.0 \% *$ \\
\hline & dentists & $70.6 \% *$ & $27.5 \%$ & $2.0 \% *$ \\
\hline \multirow{2}{*}{ Q6 - treatment measures } & students & $22.4 \% *$ & $69.0 \%$ & $8.6 \%$ \\
\hline & dentists & $41.2 \% *$ & $54.9 \%$ & $3.9 \%$ \\
\hline \multirow{2}{*}{$\begin{array}{r}\text { Q7 - remineralization } \\
\text { products }\end{array}$} & students & $12.9 \% *$ & $57.8 \%$ & $29.3 \%$ \\
\hline & dentists & $39.2 \% *$ & $45.1 \%$ & $15.7 \%$ \\
\hline
\end{tabular}

* statistically significant differences between students and dentists for each category

ITable 2. The qualitative assessment for the 7 multiple choice questions.

\begin{tabular}{|c|c|c|c|c|c|c|}
\hline \multirow{2}{*}{$\begin{array}{l}\text { Q4: therapeutic strategies } \\
\text { Pearson's chi-square test }=16.720 \text {, } \\
P=.010^{*}\end{array}$} & \multicolumn{2}{|c|}{ Students } & \multicolumn{2}{|c|}{ Dentists } & \multicolumn{2}{|l|}{ Total } \\
\hline & $n$ & $\%$ & $\mathbf{n}$ & $\%$ & $n$ & $\%$ \\
\hline 0 & $37 a$ & $31.9 \% *$ & $4_{b}$ & $7.8 \% *$ & 41 & $24.6 \%$ \\
\hline 1 & $1_{a}$ & $0.9 \%$ & $0_{a}$ & $0.0 \%$ & 1 & $0.6 \%$ \\
\hline 2 & $2 a$ & $1.7 \%$ & $0_{a}$ & $0.0 \%$ & 2 & $1.2 \%$ \\
\hline 3 & $9_{a}$ & $7.8 \%$ & $3 a$ & $5.9 \%$ & 12 & $7.2 \%$ \\
\hline 4 & $29{ }_{a}$ & $25.0 \%$ & $13_{a}$ & $25.5 \%$ & 42 & $25.1 \%$ \\
\hline 5 & $33 a$ & $28.4 \% *$ & $26_{b}$ & $51.0 \% *$ & 59 & $35.3 \%$ \\
\hline 6 & $5 a$ & $4.3 \%$ & $5 \mathrm{a}$ & $9.8 \%$ & 10 & $6.0 \%$ \\
\hline Total & 116 & $100.0 \%$ & 51 & $100.0 \%$ & 167 & $100.0 \%$ \\
\hline
\end{tabular}

* statistically significant differences between students and dentists for each category

Items were simple, short, and written in the native language of the respondents. It was considered that a 10-item questionnaire was short enough to avoid respondents experiencing fatigue or loss of motivation during completion. The experts reviewed the items in order to make sure they were accurate, free of item construction problems, and grammatically correct. Minor modifications were made to the instrument to achieve the objectives of the study.

Content and face validation were obtained by circulating the questionnaire to 15 senior dental students and five young dentists (others than the ones we recruited for the study). They concluded that the questionnaire items were clear, easy, valid, and covered all the main subjects regarding the knowledge of $\mathrm{DH}$.

The survey instrument recorded the respondent's gender and age. The subjects were asked to respond
7 multiple choice questions about the description of the pain in $\mathrm{DH}$, triggering factors, predisposing factors, treatment strategies, preventive measures, treatment measures, and remineralization products. The matrix question was about the etiological factors of dental wear (abrasion, abfraction, and erosion), and the true/false question had subscales about the main characteristics of $\mathrm{DH}$.

The open-ended question asked the participants to give an example of desensitizing toothpastes that participants may have knowledge of being efficient in $\mathrm{DH}$ treatment.

We used a quantitative evaluation by scoring each response between 0-6 points according to the number of correct answers identified, first 7 questions had between 2-4 correct answers (for each incorrect answer given or correct answer missed 1 point was deducted; a single answer given scored 0 points). Question no.8 scored 0 or 6 , for question 
ITable 3. Results obtained by students and dentists at Q7.

\begin{tabular}{|c|c|c|c|c|c|c|}
\hline \multirow{2}{*}{$\begin{array}{l}\text { Q7: Remineralization strategies } \\
\text { Pearson's Chi-square Test }=39.981 \text {, } \\
P=.000^{* *}\end{array}$} & \multicolumn{2}{|c|}{ Students } & \multicolumn{2}{|c|}{ Dentists } & \multicolumn{2}{|l|}{ Total } \\
\hline & $\mathbf{n}$ & $\%$ & $\mathbf{n}$ & $\%$ & $\mathbf{n}$ & $\%$ \\
\hline 0 & $31_{a}$ & $26.7 \% *$ & $2 b$ & $3.9 \% *$ & 33 & $19.8 \%$ \\
\hline 1 & $0_{a}$ & $0.0 \%$ & $1_{a}$ & $2.0 \%$ & 1 & $0.6 \%$ \\
\hline 2 & $3 a$ & $2.6 \%$ & $5_{b}$ & $9.8 \%$ & 8 & $4.8 \%$ \\
\hline 3 & $44_{a}$ & $37.9 \%$ & $11_{b}$ & $21.6 \%$ & 55 & $32.9 \%$ \\
\hline 4 & $23 a$ & $19.8 \%$ & $12 \mathrm{a}$ & $23.5 \%$ & 35 & $21 \%$ \\
\hline 5 & 8 a & $6.9 \% *$ & $19 \mathrm{~b}$ & $37.3 \% *$ & 27 & $16.2 \%$ \\
\hline 6 & $7_{a}$ & $6.0 \%$ & $15_{a}$ & $2.0 \%$ & 8 & $4.8 \%$ \\
\hline Total & 116 & $100.0 \%$ & 51 & $100.0 \%$ & 167 & $100.0 \%$ \\
\hline
\end{tabular}

* statistically significant differences between students and dentists for each category

ITable 4. Global score obtained of each group.

One-Sample Kolmogorov-Smirnov Test $p=.000^{*}$

Mann-Whitney $U=1466.500, p=.000^{* *}$

\begin{tabular}{|c|c|c|c|c|c|c|}
\hline Group & $\mathbf{N}$ & Mean & $\begin{array}{c}\text { Standard } \\
\text { deviation }\end{array}$ & $\begin{array}{c}\text { Standard } \\
\text { error of the } \\
\text { mean }\end{array}$ & Minimum & Maximum \\
\hline student & 116 & 40.471 & 7.8261 & .7266 & 8.0 & 52.8 \\
\hline dentist & 51 & 46.306 & 7.1557 & 1.0020 & 8.4 & 54.6 \\
\hline Total & 167 & 42.253 & 8.0697 & .6245 & 8.0 & 54.6 \\
\hline
\end{tabular}

no.9 each correct association scored 2 points, and for question no. 10 each correct answer scored 1.2 points. The maximum overall score of the questionnaire was 60 points. For the qualitative assessment, each response was evaluated as follows:

- from 0-2 points = Insufficient,

- 3-4 points $=$ Satisfactory,

- 5-6 points $=$ Good.

The participants' overall knowledge was categorized using modified Bloom's cut-off point, as good if the score was between 80 and 100\% (48-60 points), satisfactory if the score was between 50 and $79 \%$ (30-47 points), and insufficient if the score was less than $50 \%$ ( $<30$ points).

\subsection{Statistical Analysis}

The data obtained were fed into Microsoft Excel (Microsoft Inc., USA). The statistical software SPSS 20.0 (IBM Inc., USA) was used for data analysis. The standard descriptive methods were applied to determine the characteristics of the sample. Pearson's Chi-square test was applied to compare categorical variables between the groups.

We used nonparametric Mann-Whitney $U$ and OneSample Kolmogorov-Smirnov tests to evaluate the differences in the distribution of the age data set and data from the true/false question.
The confidence interval was set to $95 \%$ and p-values less than 0.05 were considered statistically significant.

\section{RESULTS}

The response rate for dental students was $87.87 \%$ (116 questionnaires returned from 132), and for young doctors this was $10.2 \%$ (51 questionnaires returned from 500). The mean age of the participants was $26.34 \pm 3.635$ years. Most participants were students $(69.5 \%)$ and $30.5 \%$ were doctors. The results showed that $61.1 \%$ were female participants and $38.9 \%$ males.

The qualitative assessment for the seven multiple choice questions is presented in Table 1. The percentage of young doctors having a good level of knowledge was statistically significantly higher than the one of dental students (Pearson's Chi-square Test, $\mathrm{p}<0.05)$.

Regarding the characterization of dentin hypersensitivity, 27 out of all subjects (16.2\%) did not know the correct answer, while the majority of subjects (105 subjects - 62.9\%) obtained the maximum score. The comparative study of the results obtained by students and doctors revealed statistically significant differences (Pearson's Chi-square Test, $p=0.001$ ). 
The percentage of students who did not know how to characterize dentin hypersensitivity was significantly higher than the doctors' percentage as seen in Figure 2.

For the question regarding the triggering factors of $\mathrm{DH}, 31.7 \%$ of all respondents obtained the maximum score. There was a statistically significant difference (Fig. 3) between the percentage of doctors (45.1\%) and that of students (25.9\%) who obtained a maximum score of 6 (Pearson's Chi-square Test, $p$ $=0.032$ ).

The third question analyzed the knowledge of the predisposing factors that determine the appearance of $\mathrm{DH}$. Figure 4 shows that a significantly higher percentage of doctors $(37.7 \%)$ than of students (16.4\%) scored a maximum of 6 points, while a significantly higher percentage of students $(12.1 \%)$ than of doctors scored 4 points.

Table 2 shows the scores obtained by students and dentists for question no. 4 regarding the therapeutic strategies.

The fifth item looked into the knowledge regarding the preventive measures for $\mathrm{DH}$. The comparative evaluation of doctors and students showed statistically significant differences (Pearson's Chisquare Test, $p=0.001$ - Fig. 5).

Analyzing the results of the sixth question regarding the treatment measures of $\mathrm{DH}$ we identified statistically significant differences (Pearson's chisquare Test, $\mathrm{p}=0.040$ ) between the $5.9 \%$ of the young doctors that obtained the maximum score compared with none of the students (Fig. 6).

The results obtained for the seventh question about remineralization strategies are shown in Table 3.

On the open-ended question, namely question eight, 160 participants (95.8\%) were able to give examples of desensitizing toothpastes. There were no statistically significant differences (Pearson's Chisquare Test, $p=0.340$ ) between the answers given by the students compared with the doctors.

Item number nine analyzed the knowledge about the etiology of different types of dental wear (abrasion, abfraction, and erosion). Most participants (63.5\%) obtained the maximum score, and $7.8 \%$ of the subjects failed to make any correct association. There were no statistically significant differences (Pearson's Chi-square Test, $\mathrm{p}=0.052$ ) between the answers given by the students compared with the doctors.

The last question evaluated the knowledge of some of the main characteristics of the $\mathrm{DH}$. The average score recorded was $3.959 \pm 1.2037$, and no statistically significant differences (One-Sample Kolmogorov-Smirnov Test $p=.000^{*}$, Mann-Whitney $U=2689.500, p=0.328$ ) were obtained between students and doctors.

The subjects' answers to the questionnaire were also quantified using an overall score, with values between 8 and 54.6. The average score recorded at the level of the whole group was $42.253 \pm 8.0697$ - a value that proved subjects had average knowledge of dentin hypersensitivity, as seen in Table 4. There were statistically significant differences between the performances of doctors and students in this questionnaire, indicating that doctors had a higher level of knowledge than students on the investigated subject.

\section{DISCUSSION}

The current research is one of the first studies that aimed to establish whether the knowledge of young doctors differs from the knowledge of senior dental students regarding their theoretical information about the dentin hypersensitivity. The high students' response rate can be due to the setting in which the questionnaires were collected, as soon as they were filled. We observe a similar response rate $(75.7$ $-78.7 \%)$ to the one reported in other studies that analyzed dental students $[3,9]$. The doctors' response rate was lower, mainly because the interaction with the participants was on-line. Additionally, the lack of knowledge and understanding of the subject might have prevented them from filling in and returning the questionnaire [17]. These data (response rate of $10.2 \%$ in the current study) are also in line with the low response rate $(7 \%)$ reported by the Canadian Advisory Board on Dentin Hypersensitivity in a similar study regarding the practitioners' understanding and clinical management of $\mathrm{DH}[8]$.

Our study revealed that most participants knew that the short and sharp pain is characteristic for $\mathrm{DH}$, which is an important step in correctly diagnosing this disease. The first clinical data that a practitioner must collect cover the history of the patient's pain $[8,18]$.

In the present study, most participants had a good performance on the evaluation of all triggering factors (thermal, tactile, evaporative, chemical stimuli) of $\mathrm{DH}$, but young doctors had a significantly better performance than students. In other studies, $92 \%$ of the surveyed dentist identified chemical and thermal stimuli as the main triggering factors for $\mathrm{DH}$ [2]. Amarasena et al. [19] observed that cold stimuli were the most frequently cited trigger of $\mathrm{DH}(67.5 \%)$. An earlier study reported the participants' lack of knowledge because the doctors had identified bruxism and malocclusion as triggers of $\mathrm{DH}$ even though neither has been recognized as a major causative factor [8].

Most participants had a good performance when asked to identify multiple predisposing factors (tooth erosion, dentin exposure, gingival recession) of DH. Comparatively, young doctors performed better than the senior dental students on this specific item. The data are consistent with other studies that have reported abrasion and gingival recession as the most important predisposing factor for $\mathrm{DH}[1,19]$. The dental professional should identify and remove predisposing factors as a first step approach when 
treating patients with $\mathrm{DH}[18]$. Less than half of the respondents knew the therapeutic strategies for $\mathrm{DH}$. One-third of the dental students and four doctors obtained a null score on this question, which means an insufficient level of knowledge. This question did not appear in other questionnaire-based studies that we found in our scientific literature search.

The preventive measures were identified by twothirds of the young doctors and more than onethird of the students, and half of all respondents performed well on this item. This is in agreement with the studies of Benoist et al. [2] (where 78\% of the dentists recognized the preventive measures) and Nazir et al. [3] where the most common preventive strategy $(74.1 \%)$ used by dental students and interns was the proper education on toothbrushing technique.

As to identifying the correct treatment of $\mathrm{DH}$, the data revealed that less than one-third of all participants obtained a good performance score, most of them having only satisfactory results. The mostly recognized treatment strategies were the correction of toothbrushing technique and the use of desensitizing toothpastes, which is consistent with other studies $[2,3,9,19]$. Less than ten percent of all respondents failed to answer this item correctly. This is in agreement with the result obtained by Cunha-Cruz et al. [20].

Half of all participants had satisfactory knowledge about the remineralization strategies used in the treatment of $\mathrm{DH}$, but one-third of them did not know the answer.

Almost all of the participants had knowledge of and could mention at least one brand of desensitizing toothpaste. That is in conformity with the findings of Benoist et al. [2], but as different from another study which has shown that fifty percent of the dentists reported incorrectly that the most popular desensitizing ingredients in desensitizing toothpastes are fluoride compounds [8].

Almost two-thirds of the participants in our study were able to recognize the etiology of different types of dental wear (as abrasion, abfraction, and erosion). Less than half of the young dentists and almost half of the dental students obtained a good result in identifying some of the main characteristics of $\mathrm{DH}$.

The mean global score of the questionnaire proved that subjects had an overall average level of knowledge of dentin hypersensitivity. No participant obtained the maximum score or a score zero.

The null-hypothesis was rejected. There were multiple results with statistically significant differences $(p<$ 0.05 ) between the two groups. This demonstrates that young dentists have a higher level of knowledge of $\mathrm{DH}$ when comparing to the students. We believe that the differences between groups are explained by the higher practical experience that doctors accumulate in time, although dental students studied DH more recently. This demonstrates that theoretical knowledge needs to be completed by practice and vice-versa.

Given the high prevalence of $\mathrm{DH}$ and its complexity, the results of this study point to the stringent need to provide better theoretical, but also clinical teaching opportunities to students and good access to continued educational programs to young doctors. These will contribute to a better quality of care for patients having this pathology. To date, there is no evidence of such an observational study being undertaken in dentistry, but it is our belief that such a design would lead to interesting and significant insights for the field. The limitations of the study are the decreased overall response rate obtained and the restricted population of undergraduate students belonging to the same university. Further multicenter studies are required in order to allow for these results to be confidently generalized into a wider population of general dental practitioners and senior dental students.

\section{CONCLUSION}

The findings of this study indicate that dentists under five-years' working experience have significantly better knowledge as compared to 6th-year dental students. Both groups of participants were far better informed regarding $\mathrm{DH}$ pain characterization, triggering factors, and predisposing factors of this condition, and less about its treatment.

\section{CONFLICT OF INTEREST}

The authors declare no conflict of interest.

\section{AUTHOR CONTRIBUTIONS}

EB: conception and design of the study, acquisition of data, analysis and interpretation of data, drafting the article, final approval of the version to be submitted. SS: drafting the article, revising the article critically for important intellectual content. AG: acquisition of data, analysis and interpretation of data. IN: acquisition of data, analysis and interpretation of data. GP: acquisition of data, analysis and interpretation of data. SA: conception and design of the study, revising the article critically for important intellectual content, final approval of the version to be submitted.

\section{ACKNOWLEDGMENTS}

The authors would like to thank all participants in the study who provided their fullest cooperation. 


\section{REFERENCES}

1. Kopycka-Kedzierawski DT, Meyerowitz C, Litaker MS, et al. Management of Dentin Hypersensitivity by National Dental Practice-Based Research Network practitioners: Results from questionnaire administered prior to initiation of a clinical study on this topic. BMC Oral Health. 2017:17:41. doi: 10.1186/s12903017-0334-0

[Full text links] [PubMed] Google Scholar Scopus WoS

2. Benoist FL, Ndiaye FG, Faye B, et al. Knowledge of and management attitude regarding dentin hypersensitivity among dentists from a West African country. J Contemp Dent Pract. 2014;15(1):86-91. doi: 10.5005/jp-journals-10024-1493 [Full text links] [PubMed] Google Scholar Scopus

3. Nazir MA, Almas K, Majeed MI, Majeed A, Ahmed SZ. A cross sectional study of dentin hypersensitivity among dental students and interns. J Int Dent Med Res. 2018;11(2):376-382.

[Full text links] Google Scholar Scopus

4. Amarasena N, Spencer J, Ou Y, Brennan D. Dentine hypersensitivity in a private practice patient population in Australia. J Oral Rehabil. 2011;38(1):52-60. doi: 10.1111/j.13652842.2010.02132x

[Full text links] [PubMed] Google Scholar Scopus WoS 5. West NX. Dentine hypersensitivity: Preventive and therapeutic approaches to treatment. Periodontol 2000. 2008;48(1):31-41. doi: 10.1111/j.1600-0757.2008.00262.x

[Full text links] [PubMed] Google Scholar Scopus WoS 6. Holland GR, Narhi MN, Addy M, Gangarosa L, Orchardson R. Guidelines for the design and conduct of clinical trials on dentine hypersensitivity. J Clin Periodontol. 1997;24(11):808-813. doi: 10.1111/j.1600-051x.1997.tb01194x

[Full text links] [PubMed] Google Scholar Scopus WoS

7. Gillam DG, Seo HS, Bulman JS, Newman HN. Perceptions of dentine hypersensitivity in a general practice population. J Oral Rehabil. 1999;26(9):710-714. doi: 10.1046/j.13652842.1999.00436x.

[Full text links] [PubMed] Google Scholar Scopus WoS 8. Canadian Advisory Board on Dentin Hypersensitivity. Consensus-Based Recommendations for the Diagnosis and Management. J Can Dent Assoc. 2003;69(4):221-226.

[Full text links] [PubMed] Google Scholar Scopus

9. Majeed A, Alshwaimi E, Nazir MA, Almas K. Dental Students' Perception of Dentine Hypersensitivity and Awareness about its Management. J Clin Diagnostic Res. 2019;13(8):ZC15-ZC19.

[Full text links]

10. Lima TC, Vieira-Barbosa NM, Grasielle de Sá Azevedo C, et al. Oral Health-Related Quality of Life Before and After Treatment of Dentin Hypersensitivity With Cyanoacrylate and Laser. J Periodontol. 2017:88(2):166-172 doi: 10.1902/jop.2016.160216 [Full text links] [PubMed] Google Scholar Scopus WoS
11. Machado AC, Rabelo FEM, Maximiano V, et al. Effect of inoffice desensitizers containing calcium and phosphate on dentin permeability and tubule occlusion. J Dent. 2019;86:53-9. doi: 10.1016/j.jdent.2019.05.025

[Full text links] [PubMed] Google Scholar Scopus

12. Bekes K, John MT, Schaller HG, Hirsch C. Oral health-related quality of life in patients seeking care for dentin hypersensitivity. J Oral Rehabil. 2009;36(1):45-51. doi: 10.1111/j.13652842.2008.01901.x

[Full text links] [PubMed] Google Scholar ScopusWoS 13. Boynton PM, Greenhalgh T. Hands-on guide to questionnaire research: Selecting, designing, and developing your questionnaire. BMJ. 2004;328(7451):1312-1315. doi: 10.1136/ bmj.328.7451.1312

[Full text links] [PubMed] Google Scholar Scopus WoS

14. Schuurs AHB, Wesselink PR, Eijkman MAJ, Duivenvoorden $H J$ Dentists' views on cervical hypersensitivity and their knowledge of its treatment. Dent Traumatol. 1995;11(5):240-244. doi:

10.1111/j.1600-9657.1995.tb00496.x

[Full text links] [PubMed] Google Scholar Scopus WoS

15. Gillam DG, Bulman JS, Eijkman MAJ, Newman HN. Dentists' perceptions of dentine hypersensitivity and knowledge of its treatment J Oral Rehabil 2002·29(3):219-225 doi: 10.1046/j.1365-2842.2002.00812.x

[Full text links] [PubMed] Google Scholar Scopus WoS

16. Tsang S, Royse CF, Terkawi AS. Guidelines for developing, translating, and validating a questionnaire in perioperative and pain medicine. Saudi J Anesth. 2017;11(5):80-9. doi: 10.4103/sja. SJA 20317

[Full text links] [PubMed] Google Scholar Scopus WoS

17. Pereira R, Gillam D, Bapatla S, Satyamurthy P. Awareness of Dentine Hypersensitivity among General Dental Practitioners in Mumbai, India. J Odontol. 2018:2(1):1-6.

[Full text links] Google Scholar

18. Gillam DG. Treatment Modalities for Dentin Hypersensitivity. In: Taha S, Clarkson BH, editors. Clinician's Guide to the Diagnosis and Management of Tooth Sensitivity. First ed. Heidelberg: Springer; 2014. doi:10.1007/978-3-642-45164-5 Google Scholar

19. Amarasena N, Spencer J, Ou Y, Brennan D. Dentine hypersensitivity - Australian dentists' perspective. Aust Dent J. 2010;55(2):181-187. doi: 10.1111/j.1834-7819.2010.01223.x [Full text links] [PubMed] Google Scholar Scopus WoS

20. Cunha-cruz J, Wataha JC, Manning W, et al. Treating Dentin Hypersensitivity: Therapeutic Choices Made by Dentists of the Northwest PRECEDENT Network. JADA. 2010;141(9):1097-1105. doi: 10.14219/jada.archive.2010.0340

[Full text links] [PubMed] Google Scholar Scopus WoS
Emilia BOLOGA

DDS, PhD Student Department of Odontology Periodontology and Fixed Prosthodontics Faculty of Dental Medicine "Grigore T. Popa" University of Medicine and Pharmacy of Jassy Jassy, Romania

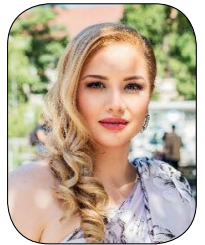

Emilia Bologa, DDS, received her degree in dentistry in 2014 from the „Gr. T. Popa” University of Medicine and Pharmacy, Jassy. Dr. Bologa is currently a PhD student at the Department of Odontology, Periodontology and Fixed Prosthodontics, Faculty of Dental Medicine, "Grigore T. Popa” University of Medicine and Pharmacy of Jassy, Jassy, Romania. She is a young researcher whose area of interest includes dentin hypersensitivity and remineralization strategies. 


\section{Ouestions}

\section{Dentin hypersensitivity is described as:}

$\square$ a. A diffuse pain;

b. A pulsating pain;

ac. A short, sharp pain;

$\square d$. An aching pain.

\section{Patients with sensitive teeth experience discomfort while:}

口a. Flossing;

ab. Jogging;

ac. Sleeping;

d. Brushing their teeth.

3. According to the results of this study, which percentage of participants have been able to give examples of desensitizing toothpastes?

口a. $88.5 \%$;

口b. $95.8 \%$;

ac. $15.8 \%$;

ad. None.

\section{What did the mean global score of the questionnaire prove?}

a. Subjects had a very good level of knowledge;

ab. Subjects had a good level of knowledge;

uc. Subjects had an average level of knowledge;

ad. Subjects had an insufficient level of knowledge.

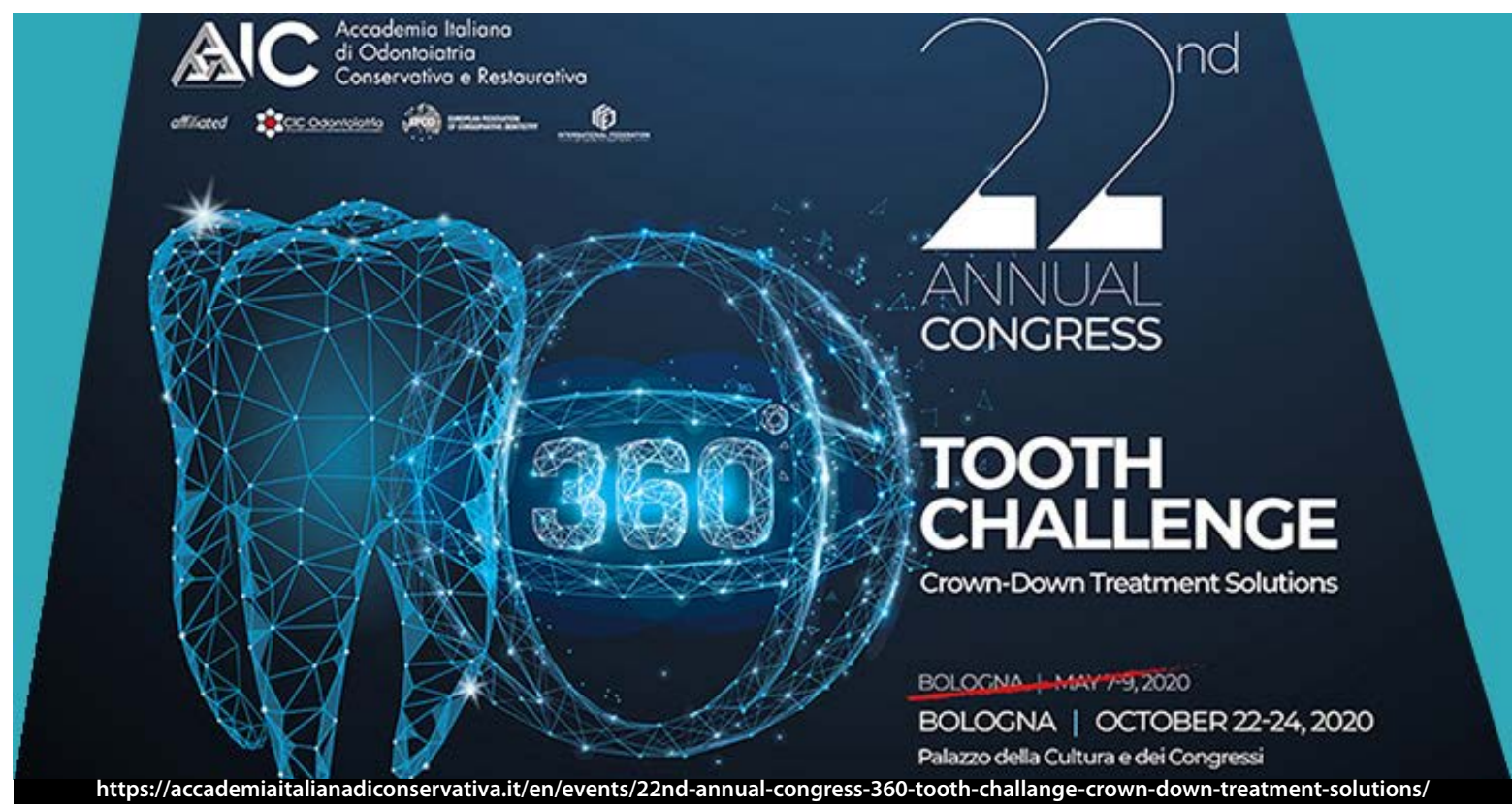

